Proceedings of the 2018 International Scientific Conference 'Economic Sciences for Agribusiness and Rural Economy' No 2, Warsaw, 7-8 June 2018, pp. 59-67

\title{
THE FARM TYPOLOGIES AND ITS PERFORMANCE IN ALBANIA (CASE OF ELBASAN)
}

\author{
Maksim Meço, PhD, Associated Professor; Ilir Kapaj, PhD, Associated Professor²; \\ Ilir Tomorri, $\mathrm{PhD}^{3}$
}

Faculty of Economy and Agribusiness, Agricultural University of Tirana

\begin{abstract}
The aim of this paper is to determine the farm typology in Elbasan region and orient policy maker's agriculture support scheme. Albania is divided into 12 regions and 61 municipality. Region of Elbasan is one of the intermediate ones ${ }^{4}$ and consists of 4 districts (district of Elbasan, Gramsh, Librazhd and Peqin). Elbasan ranked third by the availability of agricultural land in the country after Fier and Korca $(72,872$ ha or $10.4 \%$ of the agricultural land area at country level). Despite the size of the agricultural land area, it should be considered that a good part of it lies in hilly and mountainous part especially in Librazhd and Gramsh districts. Besides construction and development services, there is observed a growing trend of agricultural activity especially in terms of olive and vegetables cultivation in open field and greenhouses. In this region operate about 32,439 farms. The average farm family size is 4.9 persons, while the national average farm size is 4.5 persons (MAFCP, 2012).

The farm typology was determined using nine indicators. Based on these indicators are identified the following type of cluster/typology for Elbasani district: poly-culture for market; livestock; leisure farms; fruit trees; arable crop farm; self-sufficiency. The farm performance was determined using factors productivity which reveals that farms that belong to the poly-culture for market, livestock and self-sufficient clusters are performing better than other clusters.
\end{abstract}

Keywords: Elbasani region, farm typology, farm performance

JEL code: Q10

\section{INTRODUCTION}

During the transition period, production structures as well as other indicators that characterize the agricultural sector of a country have changed significantly in Albania. Among the factors that have influenced the orientation and decision making of farmers can be mentioned:

- Meeting the needs (it is clear that completion of consumption needs, under the conditions of subsistence farms, is one of the main motives in their decision making).

\footnotetext{
${ }^{1}$ Corresponding author: Rr. Pajsi Vodica, Kodër/Kamëz, Tirana, Albania, mmeco@ubt.edu.al, +355675 463180

${ }^{2}$ Corresponding author: Rr. Pajsi Vodica, Kodër/Kamëz, Tirana, Albania, ikapaj@ubt.edu.al, +355684013 722

${ }^{3}$ Corresponding author: Rr. Pajsi Vodica, Kodër/Kamëz, Tirana, Albania, itomorri@ubt.edu.al, +355672017908

${ }^{4}$ OECD Classification.
} 
- Availability of resources (farmers were engaged in production systems where needs for human resources are mainly provided by family farmers, and in crops whose products resists for a long time and have relatively low demands for purchased inputs).

- Incomes intensity (culture cultivation with high income per unit of surface as well as higher market opportunities).

- Experience and tradition (the farmers were oriented towards activities well-known by them).

The impact of these factors combined with the mentality, level of information and geographic location led to a total new orientation of Albanian farm production structures. In the first decade after the 1990s it is noticed the adoption of complex and multicultural production systems, characterised by a large number of agricultural crops and animals.

A part of the development barriers identified above continue to be major obstacles to farm development. Surface of agricultural land has relatively little decreased (according to the latest official statistics). It results to be 696,000 ha, because of changing its destination into non-agricultural (mainly for urban use), but an important issue remains the fallow land mainly because of emigration and urban migration. Thus, the number of farms, which have left partially or completely fallow land are estimated at 91,251 farms (MAFCP, 2014).

During the last two decades of market economy, due to the major demographic movements and displacement of population to urban areas, the number of farms with productive activity has fallen significantly. Today, the number of farms in operation is estimated to be nearly 350,654 (MAFCP, 2014). The average household size in Albania is high. This is mainly due to the living traditions where the household is composed by several families. This indicator is on national average of 4.7 household/farm, and can be considered as a development barrier. Likewise, number of farm families has remained almost unchanged in the last 10 years with an average of 1.1 families/farm.

\section{THEORETICAL BACKGROUND}

During the economic transition the agricultural sector of Albania has changed significantly. This process continues parallel with global trends of periods of relative consolidation. The diversity of farm types is increasing in terms of both their production structure and production organization. Even though the farms are still small in terms of the average size, there is an increasing tendency of fallow land, due to emigration and migration of the rural population (Boeckhout and McClements, 2010). This is mainly due to traditions, because households composed of several families use greater parts of farm land for subsistence. Region of Elbasani is part of the central statistical region, according to second level of Eurostat. Annual income per capita in 2009 according to Eurostat statistics for Elbasani Region is about 287 thousand ALL (EUR 2,0535), about 20\% lower than the national average (LSMS, 2012). Meanwhile, the level of poverty in two mountainous districts of the region (Librazhd and Gramsh) is $2 \%$ higher than the national average (MAFCP, 2012). Besides construction and development services, there is observed a growing trend of agricultural activity especially in terms of olive and vegetables cultivation in open field and greenhouses. In this region operate about 32,439 farms. The average farm family size is 4.9 persons, while the national average is 4.5 persons (MAFCP, 2012). As to the age structure of family farms, it is evidenced a relatively young age of the family farm with about $66 \%$ of the population aged from 15 to 54 years. Determining the farm typology in Elbasani region can help the policy-makers to orient their support program towards specific type of farms contributing though to enlarge their production and resource employment (labour included) and reduce poverty in rural area.

\section{MATERIALS AND METHODS}

This study was focused on the assessment and analysis of detailed data that are collected through structured questionnaires in selected farms. The main source of information for our study was:

\footnotetext{
${ }^{5}$ Exchange rate EUR $1=$ ALL 139.38. (http://ec.europa.eu/budget/contracts_grants/info_contracts/inforeuro/inforeuro_ en.cfm, Accessed 15.06.2014).
} 
- survey conducted with farmers of Elbasan district, to estimate and value rigorously according to the methodology of sample selection,

- data provided through official sources (District Statistics, INSTAT, MoAFCP),

- consultation with fields expert,

- similar studies conducted in this field.

During the period foreseen for the action plan (data collection) and based on study criteria and methodological framework, 497 face to face interviews with farmers were conducted throughout the region. This phase was proceeded by presenting of questionnaires and their adjustment according to the problems identified. Farm typology is determined based on the following indicators:

- $\%$ of sold production / total production,

- $\%$ of watered surface / total surface,

- $\%$ of livestock production / total livestock production,

- $\%$ of agricultural production / total agricultural production,

- $\%$ of orchards production / total agricultural production,

- costs / production,

- $\%$ of cropped surface / total area,

- income outside the farm / total income,

- ALL AWU / thousand produced.

This analysis will enable the withdrawal of conclusions which can serve as a useful tool for evaluating the policies pursued, as well as the design of future policies for agriculture and rural development.

\section{RESULTS AND DISCUSSION}

Types of farms identified in Elbasan region is shown in Table 1. In this region the number of persons employed in the farm is two to three people. In connection to this indicator values from one cluster to another reflect insignificant changes. Simultaneously it is recorded that almost all typologies for one to two farm family members engage in activities outside the farm.

Table 1. Types of farms and their respective number identified in the region of Elbasan

\begin{tabular}{|l|c|}
\hline Types of farms & Number \\
\hline Poly-culture for market & 47 \\
\hline Livestock & 187 \\
\hline Leisure farms & 35 \\
\hline Fruit trees & 19 \\
\hline Arable crop farm & 58 \\
\hline
\end{tabular}

Source: calculations based on the survey.

This phenomenon is more pronounced in areas that are close to urban markets and employment opportunities are greater, but on the other hand it is a clear expression of insufficient capacity of farms in terms of ability to engage fully and with a calendar as perennial-farm labour force.

More detailed information about the structure of the family as well as persons engaged in farm activities is presented in Figure 1.

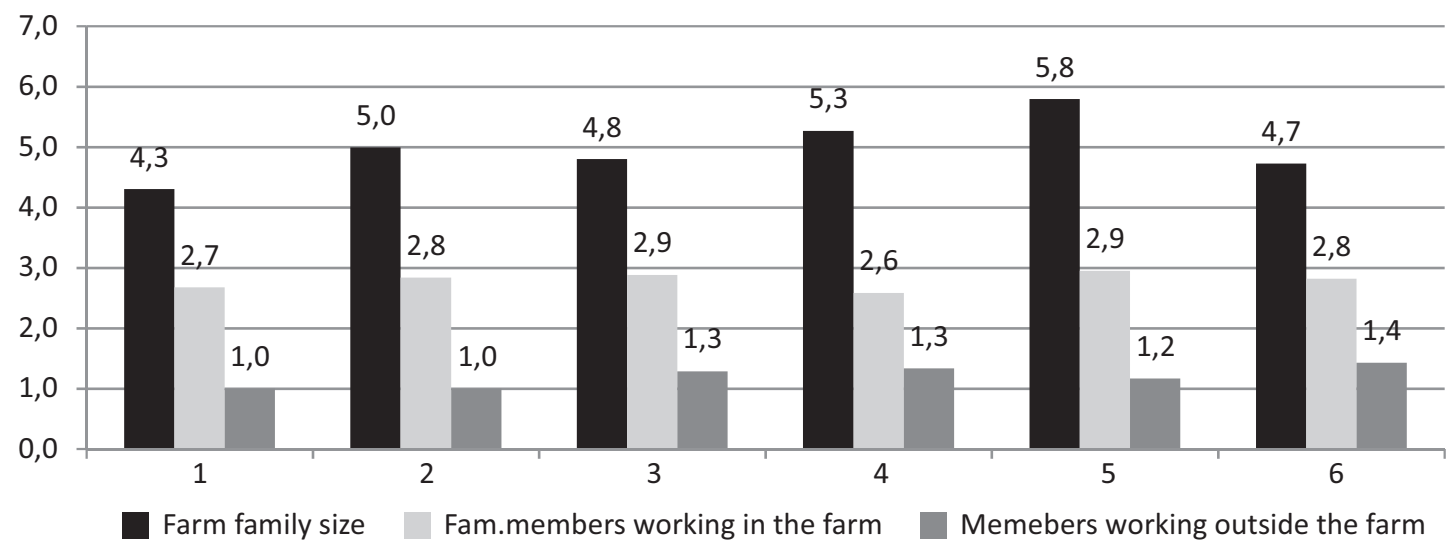

Figure 1. Farm family structure

Source: calculations based on the survey. 
Despite the presented average values from the data processing should be noted that the number of farms identified for each cluster is different and therefore their weight is just different.

\section{Land structure and farms size}

If we analyse the indicator at national level, it has a noticeable fluctuation from one district to another. What can be said with certainty (for all this is already a known fact), is that our country has a very low index of farm size. According to official statistics, the average farm size is 1.2 ha in national level. This indicator despite dramatic structural changes that have occurred in the Albanian economy has seen a very small improvement (in 2000 it was $1.04 \mathrm{~h} /$ farm) (MoAFCP, 2012). According to the same statistics, Elbasan district stands near the national average values in terms of this indicator.
Referring indicators of farm size (Fig. 2) is noted that farms typology of arable crop farm are found to be the smallest with an average area of $0.6 \mathrm{ha} / \mathrm{farm}$ and farms cluster 3 and 6 leisure farms and self-sufficiency farms result in an area of about $1.5 \mathrm{ha} / \mathrm{farm}$. Farms with livestock orientation as well as the fruit tree farms result with a size of about $0.8 \mathrm{ha} / \mathrm{farm}$, which can question the efficiency of their operations. As becomes evident from the values, this indicator has a great variation between the different typologies with about 0.9 ha.

It should be brought into attention the fact that leasing the land results in negligible values, what creates a problem that regards the intensification also increasing of farm size and specialization. Similarly high the number of plots for each farm continues to pose a barrier for this sector development.

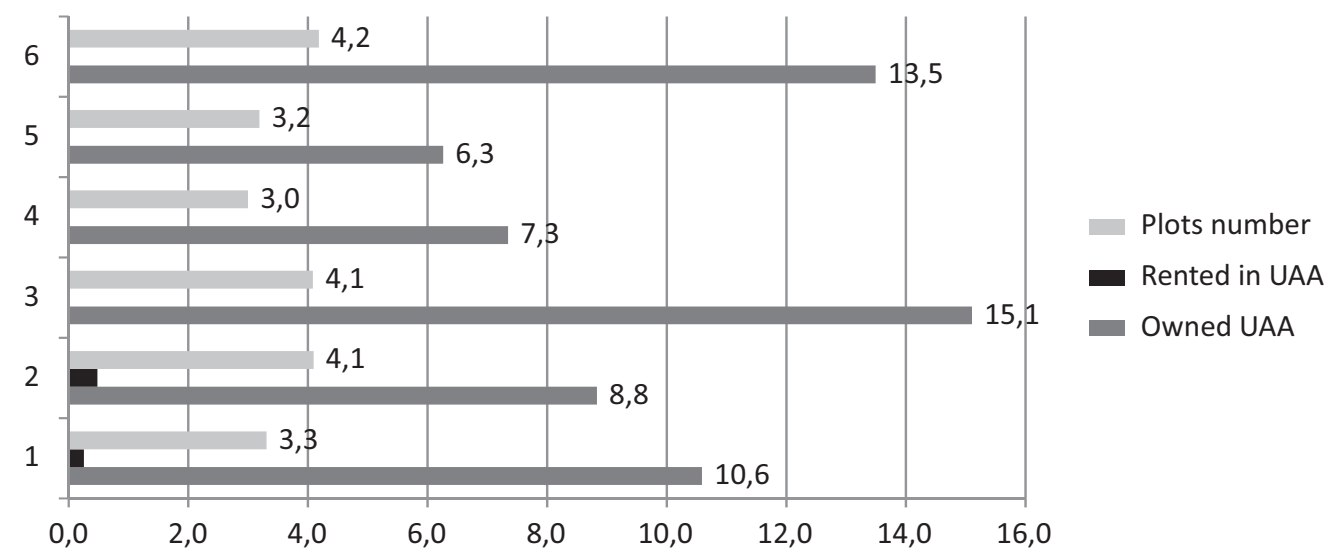

Figure 2. Farm size and plots number

Source: calculations based on the survey.

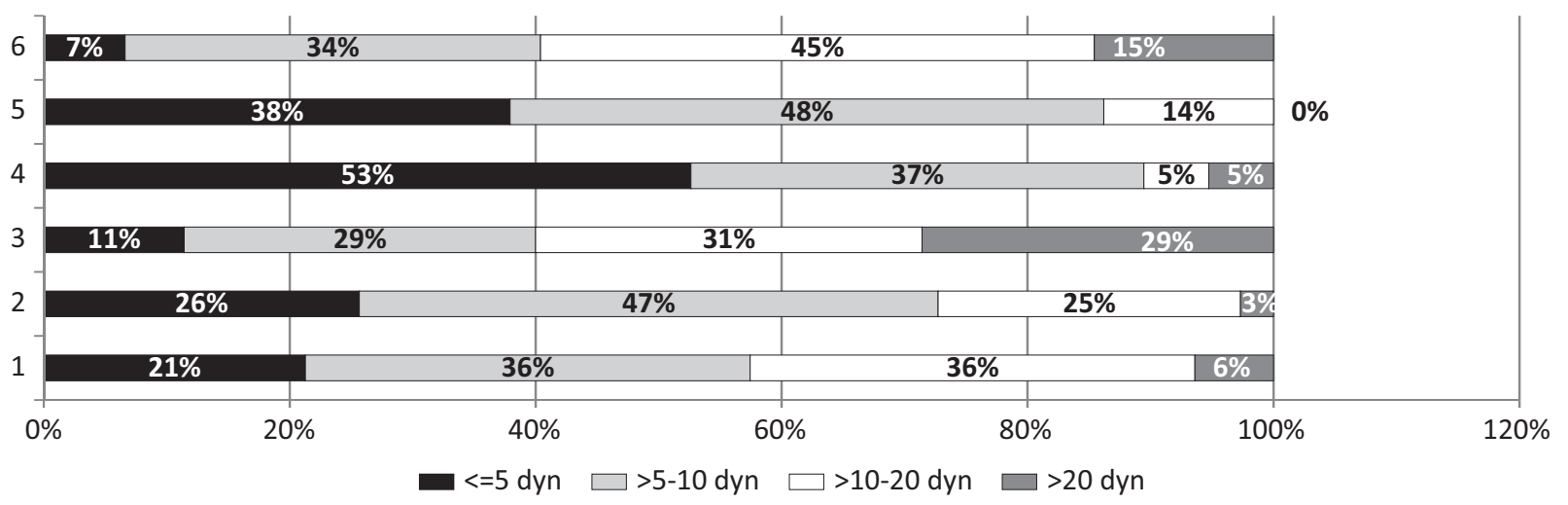

Figure 3. Farm size according typologies

Source: calculations based on the survey. 
Analysis of farm's economic performance - Case of Elbasan

Existing literature frequently divides business performance measures into financial performance, which includes factors such as revenues, profit, or stock prices, and non-financial performance measures such as reputation, loyalty, or customer satisfaction. As Louhichi et al. (2013) approach, this study will assess performance in terms of viability and productivity.

Productivity will be assessed in terms of farm net income per work units (FNI/WU), farm net income per utilized agricultural area (FNI/UAA) and farm net income per capital (FNI/C).

Viability will be assessed in terms of minimal wage $(\mathrm{MW})^{6}$ and extreme/complete poverty ${ }^{7}$ lines. Thus, the minimal wage approach is the comparison of FNI/WU with the minimal wage for 2014. The second indicator is the comparison of $\mathrm{FNI} / \mathrm{HM}$ with the poverty line. The importance of non-farm incomes in Albanian rural areas makes necessary to perform the analysis not only for the FNI but as well as for the total household income (THI). The following table shows the utilization of these two indicators.

Table 2 shows when a farm perform better or worse in terms of viability. Thus, when the calculation of viability in terms of minimal wage results more than 1 , means that the farms within that cluster are paying the work more than minimal wage. The same line of interpretation will be followed for other indicator as shown in Table 2.

\section{Farms productivity}

Productivity is a broad concept, but within this study by productivity, we mean the farm net income per work unit, per utilized agricultural area and per capital. Through these three indicators, we aim to verify how much productive are the Elbasan's agricultural units.

As shown in the Figure 4, the Elbasan's farms generally are performing positively in terms FNI/AWU. Furthermore, farms that belong to clusters such as

Table 2. Viability analysis

\begin{tabular}{|c|c|c|c|}
\hline & Indicator & Value & Note \\
\hline \multirow{3}{*}{$\begin{array}{l}\text { Minimal } \\
\text { wage }\end{array}$} & \multirow{3}{*}{$\frac{F N I}{W U \cdot 12 \cdot M W}$} & $>1$ & The work in agriculture is paid more than the minimal wage (MW) \\
\hline & & $=1$ & The work in agriculture is paid as much as the minimal wage (MW) \\
\hline & & $<1$ & The work in agriculture is paid less than the minimal wage (MW) \\
\hline \multirow{3}{*}{$\begin{array}{l}\text { Poverty line } \\
\text { Extreme } \\
\text { poverty }\end{array}$} & \multirow{3}{*}{$\frac{F N I}{H M \cdot 12 \cdot 4,037 A L L}$} & $>1$ & The members of the family live above the extreme poverty line \\
\hline & & $=1$ & The members of the family live on the extreme poverty line \\
\hline & & $<1$ & The members of the family live below the extreme poverty line \\
\hline \multirow{3}{*}{$\begin{array}{l}\text { Poverty line } \\
\text { Complete } \\
\text { poverty }\end{array}$} & \multirow{3}{*}{$\frac{F N I}{H M \cdot 12 \cdot 4,891 A L L}$} & $>1$ & The members of the family live above the complete poverty line \\
\hline & & $=1$ & The members of the family live on the complete poverty line \\
\hline & & $<1$ & The members of the family live below the complete poverty line \\
\hline
\end{tabular}

\footnotetext{
${ }^{6}$ For administrative reasons, the Albanian government fix the level of minimal wage. In 2014 the minimal monthly wage amounts ALL 22,000 (EUR 156.6).

${ }^{7}$ According to the Institute of Statistics of Albania (INSTAT), an inhabitant is in extreme poverty condition if its monthly income doesn't exceed the value of ALL 4,037 (EUR 28.7) and is a complete poverty condition if its monthly income doesn't exceed the amount of ALL 4,891 (EUR 34.8).
} 


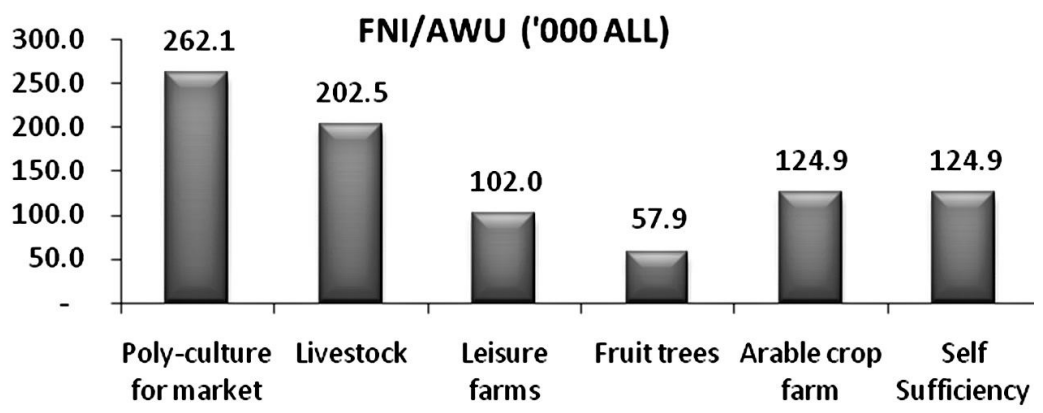

Figure 4. Farm net income per annual work unit

Source: calculations based on the survey.

Poly-Culture for market and Livestock are more productive than other clusters. These results are justified when we argue regarding the level of diversification activities. Thus, theoretically it is known the fact that the more diversified is a farm the more will take engagement the work units in activities. This means that the work units in poly-culture and livestock farms are more intensive, justifying the high level of FNI/ AWU.

In contrary to poly-culture and livestock clusters, the leisure, fruit trees, arable crop and self-sufficient farms are not so intensive regarding the work utilization during a year, justifying the low productivity.

\section{Farm viability}

The first indicator related to the viability is comparison of FNI/WU with minimal wage. The first thing we emphasize within this indicator is the closed related trend with FNI/AWU and FNI/UAA, meaning that the more intensive a farm is in terms of FNI/AWU and FNI/UAA the more high tend to pay the work.

We clearly see that all clusters are paying the work unit less then minimal wage. Except this fact, we must argue poly-culture, livestock and self-sufficient clusters, because their work payment is close to the MW. Shortly, this situation is justified by the fact that these three clusters are more intensive in terms of productivity as well. Nevertheless, the efficacy at agricultural farms still remains too low and this came as a consequence of high cost for ensuring inputs, lack of cooperation etc.

Total household income per work units compared with minimal wage. As Figure 6 shows we see the raise of clusters that had low WU payment by agricultural income. Thus, Leisure, fruit trees and arable crop farms have the highest off farm income respectively $68.5,73.3$ and $63.8 \%$.

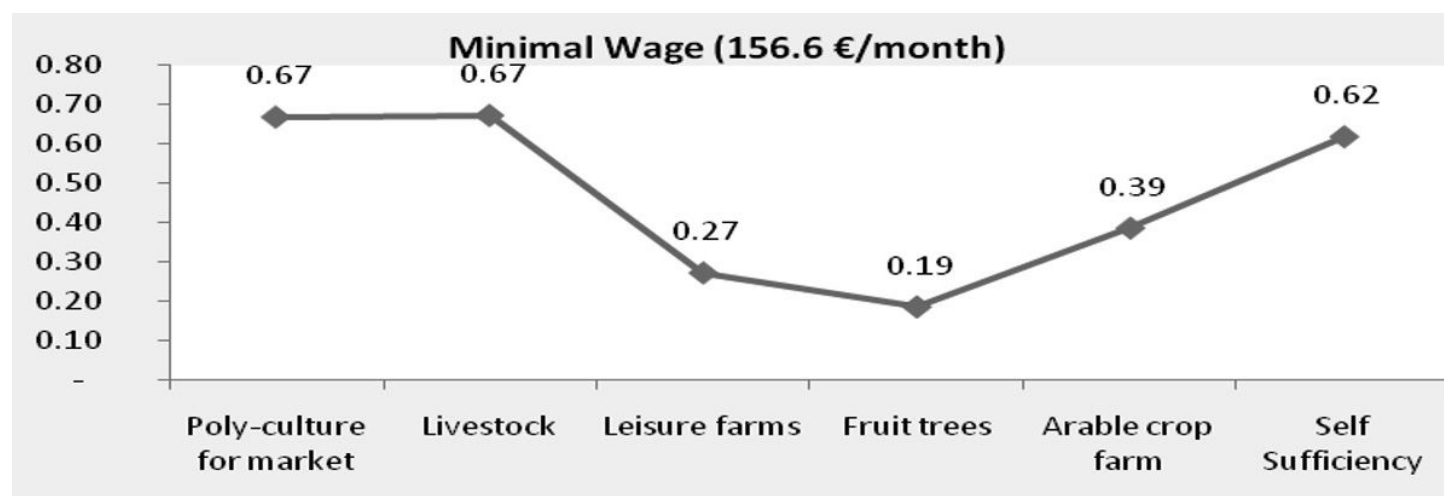

Figure 5. Minimal wage

Source: calculations based on the survey. 
THI: Minimal Wage (156.6 $€ /$ month)

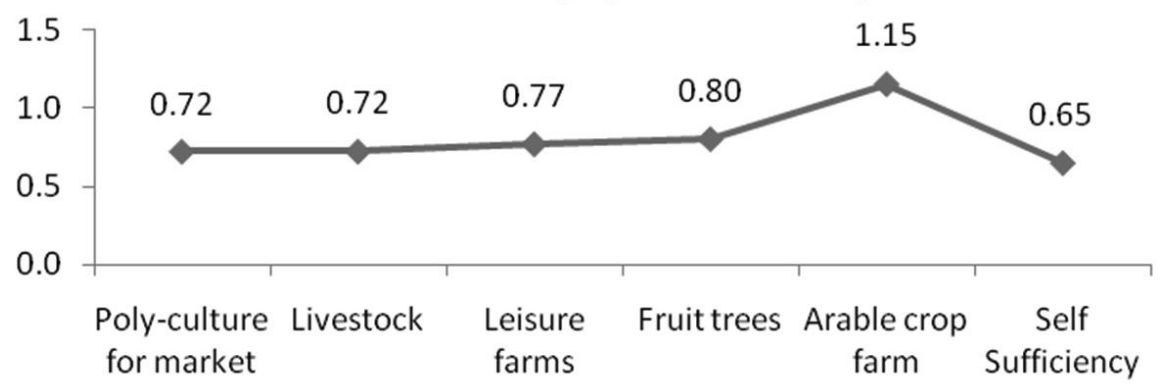

Figure 6. Total household income per work units with minimal wage

Source: calculations based on the survey.

Farm net income per work units per household member compared with extreme and complete poverty. According to the Institute of Statistics of Albania (INSTAT), an inhabitant is in extreme poverty condition if its monthly income doesn't exceed the value of ALL 4,037 (EUR 28.7) and is a complete poverty condition if its monthly income doesn't exceed the amount of ALL 4,891 (EUR 34.8). Thus, taking in account the below figure, we again conclude that families within poly-culture, livestock and self-sufficient clusters are living above extreme and complete poverty. Actually, this justifies the importance of agricultural businesses on welfare and standard living in rural areas. Additionally, even in terms of productivity and minimal wage these clusters were better performing as well.
Families of arable crop farms are living above extreme poverty but under complete poverty. Actually, the coefficient of complete poverty is close to the line of living above complete poverty, meaning this cluster is at least better performing than leisure, fruit trees clusters. When we focus on leisure, fruit trees clusters we again find them performing worse. This situation is a consequence of not having positive productivity (Fig. 7).

Total household income per household member compared with extreme and complete poverty. Figure 8 shows a clear raise on standard living of leisure, fruit trees and arable crop farms and furthermore they are better performing than other clusters. This result is fully supported by the fact that these three clusters have the highest off-farm income.

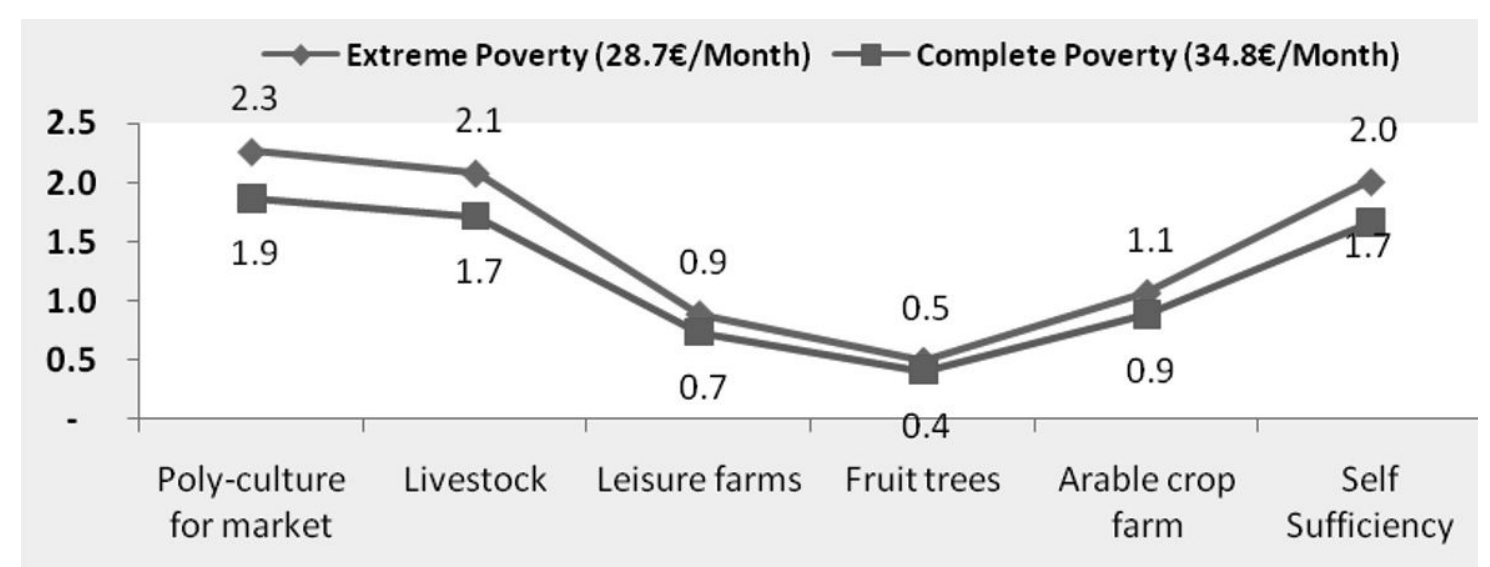

Figure 7. Farm net income per work units per household member with extreme and complete poverty Source: calculations based on the survey. 


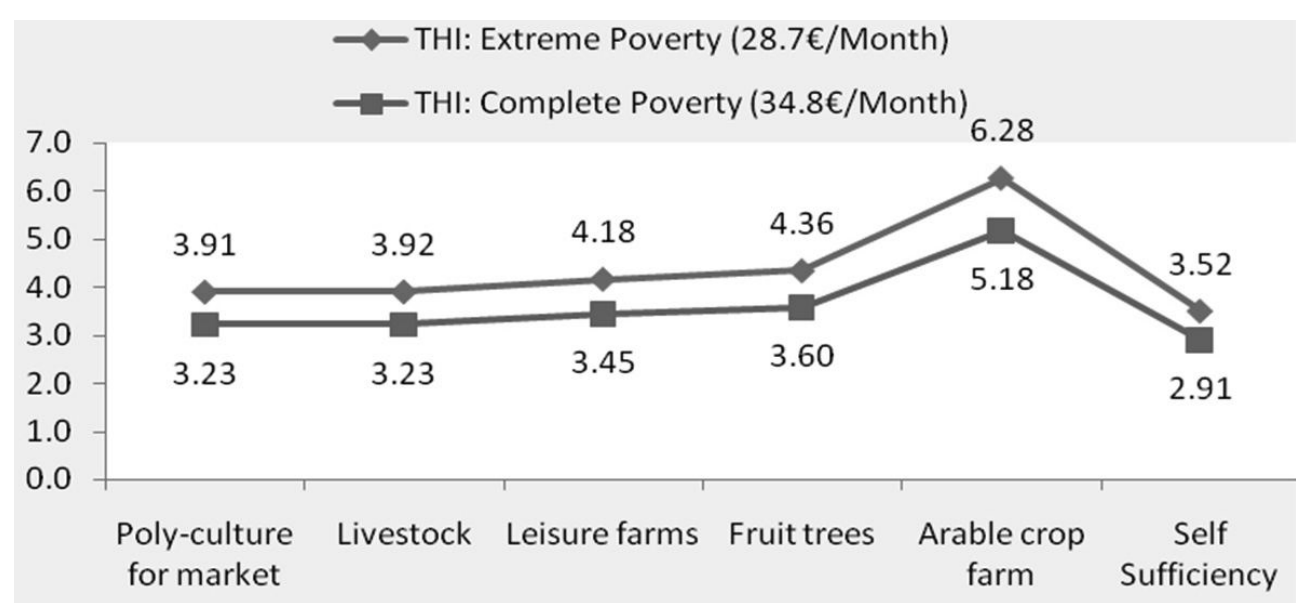

Figure 8. Total household income per household member compared with extreme and complete poverty Source: calculations based on the survey.

\section{CONCLUSIONS}

Even that we had some clusters that were not positively performing in terms of productivity and viability, we can conclude that agricultural is a very important activity for rural areas in Elbasani region. Additionally, farms that belong to the poly-culture for market, livestock and self-sufficient clusters are better performing than other clusters.

A very important issue to handle is even that most of clusters are having positive performance in terms of productivity they are still facing concerns or obstacles such as high cost, lack of horizontal integration, lack of cooperation etc. This, argument is justified by the fact that all clusters are still not capable to provide payment for the work compared to the minimal wage.

This study concludes that poly-culture farms, livestock and self-sufficient farm are more productive and viable and must be a priority to be supported by the governmental support agricultural scheme.

\section{REFERENCES}

1. Boeckhout, S., McClements, C. (2010). Regional Disparities in Albania. Retrieved from http://www.al.undp. org/content/dam/albania/docs/Regional\%20Disparitie s\%20in\%20Albania\%20-\%20Analysis.pdf [Accessed 30.05.2014].
2. Louhichi, K. et al. (2013). Modelling Agri-Food Policy Impact at Farm-household Level in Developing Countries (FSSIM-Dev). Application to Sierra Leone. Joint Research Centre. JRC Scientific and Policy Reports.

3. Ministry of Agricultural Rural Development and Water Management, MAFCP (14 April 2011). Annual Statistical Yearbook. Retrieved from http://www.bujqesia.gov.al/

4. Ministry of Agricultural Rural Development and Water Management, MAFCP (20 April 2012). Annual Statistical Yearbook. Retrieved from http://www.bujqesia.gov.al/

5. Ministry of Agricultural Rural Development and Water Management, MAFCP (April 2012). Annual Statistical Yearbook. Retrieved from http://www.bujqesia.gov.al/

6. Ministry of Agricultural Rural Development and Water Management, MAFCP (14 March 2012). Annual Statistical Yearbook. Retrieved from http://www.bujqesia. gov.al/

7. Ministry of Agricultural Food and Consumer Protection, MAFCP (11 April 2012). Annual Statistical Yearbook. Retrieved from http://www.bujqesia.gov.al/

8. Ministry of Agricultural Food and Consumer Protection, MAFCP (1 August 2012). Annual Statistical Yearbook. Retrieved from http://www.bujqesia.gov.al/

9. Ministry of Agricultural Food and Consumer Protection, MAFCP (22 November 2012). Annual Statistical Yearbook. Retrieved from http://www.bujqesia.gov.al/

10. Ministry of Agricultural Food and Consumer Protection, MAFCP (19 June 2012). Annual Statistical Yearbook. Retrieved from http://www.bujqesia.gov.al/ 
Proceedings of the 2018 International Scientific Conference 'Economic Sciences for Agribusiness and Rural Economy' No 2, Warsaw, 7-8 June 2018, pp. 59-67

11. Ministry of Agricultural Food and Consumer Protection, MAFCP (1 December 2012). Annual Statistical Yearbook. Retrieved from http://www.bujqesia.gov.al/
12. Ministry of Agricultural Food and Consumer Protection, MAFCP (21 September 2012). Annual Statistical Yearbook. Retrieved from http://www.bujqesia.gov.al/ 